\title{
REVISÃO: EFEITO DO TRATAMENTO SOB ALTA PRESSÃO SOBRE AS PROPRIEDADES FUNCIONAIS DA PROTEÍNA DE SOJA E INTERAÇÃO PROTEÍNA - POLISSACARÍDIOS
}

\author{
RENATA TORREZAN * \\ MARCELO CRISTIANINI ${ }^{* *}$
}

\begin{abstract}
Neste trabalho de revisão de literatura foram abordados aspectos da composição da proteína de soja, suas propriedades funcionais e os efeitos do tratamento sob alta pressão sobre tais proteínas. As interações de proteínas e polissacarídios (carragena e pectina) também foram estudadas, assim como os efeitos do tratamentos sob alta pressão sobre essas interações. Os estudos revisados neste trabalho evidenciaram campo de aplicação da tecnologia de alta pressão para produtos a base de proteínas e polissacarídios. Essa tecnologia pode ser empregada para controlar ou modificar as propriedades funcionais tecnológicas das proteínas, assim como para o desenvolvimento de novos produtos e futuras aplicações.
\end{abstract}

PALAVRAS-CHAVE: PROTEÍNAS DE SOJA; PROPRIEDADES FUNCIONAIS; PECTINA; CARRAGENA.

\section{INTRODUÇÃO}

O cultivo de soja para consumo humano deve se transformar em bom negócio nos próximos anos. Conforme relato de especialista em mercado internacional, veiculado pela empresa ECIRTEC (2003), o consumo de produtos de soja deverá crescer $300 \%$ nos próximos cinco anos. Segundo a empresa NUTRISOY (2003), o consumo de soja para uso humano quadruplicou nos últimos cinco anos, atingindo $4 \%$ do total de soja produzido no Brasil. O mercado brasileiro de bebidas não-alcoólicas também está em plena expansão. No primeiro semestre de 2002, as

* Pesquisadora da Embrapa Agroindústria de Alimentos, Rio de Janeiro/RJ, Doutoranda do Departamento de Tecnologia de Alimentos (DTA), Faculdade de Engenharia de Alimentos (FEA), Universidade de Campinas (UNICAMP), Campinas/SP (e-mail: torrezan@fea.unicamp.br).

** Doutor em Ciência de Alimentos, Professor da DTA/FEA/UNICAMP, Campinas, SP (e-mail: olecram@fea.unicamp.br.). 
vendas de bebidas a base de soja cresceram 104\% em volume (SOY..., 2002 e KRONES, 2002). Em entrevista à empresa NUTRISOY (2003), o pesquisador da Embrapa Soja, José Marcos Mandarino comentou que a divulgação na mídia dos benefícios da soja à saúde está ocasionando mudança no conceito dos consumidores, pois o fato do alimento conter soja passou a ser indicado com destaque no rótulo e a agregar valor ao produto. Tal informação foi confirmada pela gerência de Marketing da Unilever, que relacionou o crescimento de $40 \%$ nas vendas de bebidas a base de soja de 2001 para 2002 ao fato das pessoas desejarem comprar suco que também seja nutritivo (MELLO, 2002).

Vários processadores de alimentos nos Estados Unidos têm procurado incluir a proteína de soja em suas formulações como forma de atrair os consumidores, pois o Food and Drug Administration (FDA) permite a veiculação do emprego da proteína de soja como redutor de riscos de doenças cardíacas (SOY..., 2002). Segundo ANTONY et al. (1996), o consumo de proteína de soja está associado com sintomas da menopausa, osteoporose e cânceres de mama e de próstata, além da redução do risco de doenças cardíacas.

O objetivo desta revisão foi apresentar os aspectos da composição da proteína de soja, suas propriedades funcionais e os efeitos do tratamento sob alta pressão sobre essas propriedades e sobre as interações de proteínas com polissacarídios aniônicos (carragena e pectina).

\section{PROTEÍNA DE SOJA}

Os grãos de soja caracterizam-se por conter cerca de $20 \%$ de óleo e $40 \%$ de proteína. O óleo e grande parte da proteína encontram-se em corpúsculos especiais contidos nas células cotiledonares. A maior parte das proteínas da soja é classificada como globulinas. Essas proteínas são insolúveis em água no seu ponto isoelétrico, mas se dissolvem em água ou soluções salinas diluídas em valores de $\mathrm{pH}$ acima ou abaixo de seu ponto isoelétrico ( $\mathrm{pH} 4-5)$. As proteínas de soja quando em solução mostram-se sensíveis ao tratamento térmico (SGARBIERI, 1996).

As proteínas de soja constituem mistura de macromoléculas de tamanhos, densidades de carga e estruturas diferentes. Os pesos moleculares das proteínas de soja variam de 8.000 a 600.000, com maior concentração na faixa de 110.000 a 350.000 . A separação das proteínas por ultracentrifugação apresenta frações cujos coeficientes de 
sedimentação S (unidades Svedberg, a $20^{\circ} \mathrm{C}$ em água) são 2, 7, 11 e 15. Essa análise têm mostrado que as frações $11 \mathrm{~S}$ e $15 \mathrm{~S}$ são constituídas de proteínas puras (CHEFTEL, CUQ e LORIENT, 1989; LIU, 1997). A fração 2S, que representa cerca de $20 \%$ das proteínas, é composta por proteínas biologicamente ativas, inibidores de tripsina e globulinas 2S. As frações $7 \mathrm{~S}$ e $11 \mathrm{~S}$ representam juntas cerca de $70 \%$ das proteínas contidas no grão de soja. A fração 7S é composta pelas enzimas $\beta$ amilase e lipoxigenase, hemaglutinina e citocromo $\mathrm{C}$ e pela globulina conhecida como $\beta$-conglicinina (glicoproteína de reserva). A globulina $11 \mathrm{~S}$, também conhecida como glicinina, é proteína de reserva, constituindo cerca de $37 \%$ da proteína da soja. A fração 15S (globulina 15S) perfaz cerca de $10 \%$ do total de proteínas (SGARBIERI, 1996; CHEFTEL, CUQ e LORIENT, 1989).

A $\beta$-conglicinina, glicoproteína trimérica com peso molecular médio de $180 \mathrm{kDa}$ que representa $91 \%$ da fração $7 \mathrm{~S}$, é constituída de três subunidades $\alpha^{\prime}$ (57-83 kDa), $\alpha$ (57-76 kDa) e $\beta$ (42-53 kDa), que interagem para formar cerca de 6 isômeros conhecidos (designados como B1 a B6). Outra subunidade $\beta$ ' já foi observada em algumas variedades de soja. As subunidades $\alpha$, $\alpha$ ' e $\beta$ são ricas em asparginina, glutamina, leucina e arginina. As subunidades $\alpha$ e $\alpha$ ', similares na composição de aminoácidos, são ricas em cisteína e pobres em metionina. A subunidade $\beta$, glicoproteína formada por polipeptídios, contém 4-5\% de carboidratos e não apresenta metionina (LIU, 1997).

A fração 11S (glicinina), de estrutura hexamérica, tem peso molecular de $360 \mathrm{kDa}$. As subunidades monoméricas apresentam estrutura A-S-S-B, na qual A representa polipeptídeo ácido de 33-44 kDa, $B$ polipeptídeo básico de cerca de $20 \mathrm{kDa}$ e $\mathrm{S}$-S corresponde às pontes dissulfídicas que unem os polipeptídeos, formando a subunidade AB. Sua estrutura quaternária é ainda estabilizada por interações eletrostáticas e hidrofóbicas (LIU, 1997).

Em geral, a fração 11S contém 3 ou 4 vezes mais metionina e cisteina por unidade de proteína do que a fração 7S (KITAMURA, 1995). A fração $11 \mathrm{~S}$ torna-se bastante valiosa sob o ponto de vista nutricional visto que a soja é deficiente em aminoácidos sulfurados.

O isolado protéico de soja (IPS), que contém pelo menos $90 \%$ de proteína, é preparado a partir de flocos ou farinha de soja desengordurada que recebe tratamento térmico brando para inativar os fatores antinutricionais. 
O IPS, produto livre de carboidratos e de lipídios, é bastante utilizado como ingrediente em produtos cárneos, bebidas, produtos de panificação, alimentos infantis e em formulações especiais para nutrição clínica. Segundo SGARBIERI (1996), o processo de preparo do IPS envolve: extração da proteína de soja da farinha ou flocos desengordurados com solução alcalina diluída ( $\mathrm{pH} ~ 9,0$ ); centrifugação para eliminar o resíduo insolúvel e obter o extrato alcalino; adição de ácido até $\mathrm{pH}$ isoelétrico ( $\mathrm{pH} 4,5)$; centrifugação para obtenção do precipitado (isolado isoelétrico) e do sobrenadante "soro"; lavagem do precipitado com água fria para eliminar o resíduo do ácido; tratamento com álcali até $\mathrm{pH}$ 7-8 para dispersão do precipitado; e secagem da proteína isolada por atomização (Spray Dryer).

\section{PROPRIEDADES FUNCIONAIS DAS PROTEÍNAS DE SOJA}

As propriedades funcionais têm sido definidas como qualquer propriedade dos alimentos ou de seus componentes, excetuando-se as nutricionais, que influencie a sua aceitação e utilização (SGARBIERI, 1996). Essas dependem das propriedades físicas e químicas das proteínas, que são muito importantes para o preparo de determinados alimentos, afetando sua conservação, estocagem e aceitação pelos consumidores. Segundo CHEFTEL, CUQ e LORIENT (1989), as propriedades funcionais das proteínas podem ser classificadas em hidrofílicas, intermoleculares e interfásicas. As propriedades hidrofílicas dependem das interações proteína-água (solubilidade, capacidade de hidratação e de retenção de água, adesividade, dispersibilidade e viscosidade). As propriedades intermoleculares dependem da capacidade das interações proteínaproteína ou das moléculas de proteína com outros componentes (precipitação, gelatinização, formação de fibras e pastas protéicas). Já as propriedades interfásicas ou de superfície dependem da capacidade de união das moléculas de proteínas para formar película entre duas fases imiscíveis (tensão superficial, emulsificação e capacidade de formação de espuma).

O índice de solubilidade constitui propriedade funcional importante, pois relaciona-se diretamente com outras características funcionais como as capacidades de formação de espuma e de geleificação, o poder de emulsificação e viscosidade (MATTIL, 1971).

WAGNER E GUÉGUEM (1999) afirmaram que as propriedades emulsificantes das proteínas dependem basicamente de dois efeitos: (a) 
decréscimo substancial da tensão superficial devido à adsorção da proteína na interface água-óleo e (b) formação de barreira estrutural, eletrostática e mecânica capaz de opor-se à desestabilização das gotículas emulsionadas. A capacidade de emulsificação das proteínas depende de características físico-químicas como tamanho molecular, composição e seqüência de aminoácidos, conformação espacial, densidade das cargas e hidrofobicidade superficial (KESTER e RICHARDSON,1984).

As proteínas são susceptíveis à desnaturação tanto pelo frio como pelo calor. A etapa inicial, importante no processo de geleificação das proteínas globulares, consiste no aquecimento da solução protéica acima da temperatura de desnaturação. Após o resfriamento, os grupamentos expostos do polipeptídio desnaturado interagem, conduzindo a formação de complexa rede que atua como matriz capaz de reter água e outros componentes (DAMODARAN, 1988).

As frações $\beta$-conglicinina e glicinina mostram consideráveis diferenças funcionais no que se refere a habilidade de formação de gel, estabilidade térmica e capacidade de emulsificação (YAMAUCHI, YAMAGISHI e IWABUCHI, 1991). Em geral, a fração 11S exibe melhor habilidade para a formação de gel, principalmente quando a subunidade $A_{5} A_{4} B_{3}$ está ausente e permite a formação de tofu de textura firme. Por outro lado, a fração 7S demonstra melhor capacidade de formar emulsão e de mantêla estável. Ambas as frações $7 \mathrm{~S}$ e $11 \mathrm{~S}$ formam gel quando aquecidas e pelo uso de agentes coagulantes (sulfato de cálcio ou cloreto de magnésio), como no preparo do tofu. A fração $11 \mathrm{~S}$ requer tratamento térmico mais intenso do que a fração $7 \mathrm{~S}$ para a formação do gel. $\mathrm{Na}$ presença de sulfato de cálcio, a fração $11 \mathrm{~S}$ coagula mais rapidamente e forma agregados maiores do que a fração $7 \mathrm{~S}$. O gel formado pela fração 11 é mais rígido do que o formado pela fração $7 \mathrm{~S}$, tendo maior capacidade de retenção de água e valores de tensão maiores. Também se expande mais durante o aquecimento e é mais sensível ao efeito de amaciamento do ácido fítico em comparação com a fração 7S (Hashizume, NAKAMURA e WATANABE, 1975; LIU, 1997).

$\mathrm{O} \mathrm{pH}$ exerce forte influência sobre a funcionalidade das proteínas, visto que várias dessas propriedades funcionais dependem do estado de ionização de grupos ionizáveis na molécula protéica. Diferindo na composição e estrutura, as globulinas $\beta$-conglicinina e glicinina exibem também diferenças nutricionais e funcionais, cujo estado de associaçãodissociação e estabilidade térmica são altamente dependentes do pH e 
da força iônica (PETRUCELLI e AÑON, 1996). Assim, torna-se difícil predizer as mudanças estruturais e funcionais que podem ocorrer quando os isolados são submetidos a tratamentos diferentes. A capacidade de formação do gel e o tipo do gel formado dependem da concentração da proteína, da temperatura, do $\mathrm{pH}$, da formação e ruptura das pontes dissulfídicas e das interações eletrostáticas e hidrofóbicas (GARCíA et al., 1997). Além disso, os tipos de interações proteína-proteína e proteínaágua diferem conforme as preparações de proteína de soja (UTSUMI e KINSELLA, 1985).

\section{A TECNOLOGIA DE ALTA PRESSÃO E AS PROTEÍNAS DA SOJA}

Segundo ANSTINE (2003), as pesquisas utilizando alta pressão para a preservação de alimentos começaram no final do século XIX. Os primeiros testes realizados já indicavam que o leite cru tratado sob alta pressão mantinha-se fresco por mais tempo. No entanto, os primeiros produtos comerciais tratados sob alta pressão somente surgiram por volta de 1990 no Japão. A tecnologia de alta pressão que promove a eliminação de microrganismos e inativa enzimas, sem expor o alimento a altas temperaturas, mostrou-se viável. Tem sido cada vez mais utilizada em todo o mundo para prolongar a vida-de-prateleira dos alimentos, afetando pouco o seu conteúdo de vitaminas, sabor, textura e cor. Essa tecnologia já foi aplicada com sucesso para a preservação de geleias, iogurtes, molhos, sobremesas prontas, sucos e polpas de frutas. No Japão é utilizada também para o descongelamento de peixe, estabilização de presunto e outros produtos de pescado (GRANT, PATTERSON e LEDWARD, 2000).

O fator limitante do uso da tecnologia de alta pressão é o custo envolvido na aquisição dos equipamentos e do processamento. Avanços têm sido realizados no desenho e construção desses equipamentos para tornar os custos de processamento mais competitivos em relação à esterilização e ao congelamento. Estima-se que os custos para modificar a linha de processamento já existente para alta pressão esteja em torno de US\$ 0,0455 / libra, considerando-se a depreciação dos equipamentos como sendo de 10 anos (MEYER et al., 2000).

Há dois métodos de processamento sob alta pressão: o isostático e o de homogeneização ou dinâmico. O método isostático, denominado também como processamento a pressão ultra alta, concentra a maior 
parte dos estudos já realizados. O processo de alta pressão hidrostática (APH), como o próprio nome sugere, submete alimentos líquidos ou sólidos pré-embalados e selados em uma câmara a pressões acima de $100 \mathrm{MPa}$ ( $\cong 1.000 \mathrm{~atm})$. Nos sistemas comerciais, as pressões utilizadas estão na faixa de 400 a $700 \mathrm{MPa}$. A pressurização é realizada em espaço confinado contendo fluído (no caso da hidrostática é a água) que atua como o meio de transferência da pressão. A pressão é aplicada igualmente em todas as direções o que permite aos sólidos reterem o seu formato original. Uma das vantagens desse processo sobre os processos convencionais é que a compressão isostática independe do tamanho e geometria do produto. A pressão aplicada e o tempo de aplicação irão depender do tipo do produto a ser tratado e do produto final desejado. Normalmente, a inativação enzimática requer o uso de pressões mais elevadas do que a inativação microbiana (SAN MARTíN, BARBOSA-CÁNOVAS, SWANSON, 2002). O processo de pressão dinâmico (PHD) ou contínuo (fluxo) é o sistema no qual dois pistões operam simultaneamente, sendo que enquanto um é preenchido com o alimento o outro o empurra contra a válvula de homogeneização. Esse processo baseia-se na movimentação dos fluídos e na ação de forças instantâneas que agem sobre os sólidos imersos nesses líquidos. A destruição dos microrganismos ocorre pela ruptura da célula causada pelo aumento da pressão e tensão de cisalhamento. O processo é instantâneo, ocorrendo em mili-segundos. As pressões utilizadas estão na faixa de 30 a $350 \mathrm{MPa}$. O alimento deve ser embalado ao final do processo em embalagem asséptica (WILLIAMS-CAMPBELL e SOLOMON, 2002; GRANT, PATTERSON e LEDWARD, 2000).

O uso da alta pressão para modificar a funcionalidade das proteínas foi revisado por MESSENS, VAN e HUYGHCEBAERT (1997). Segundo tais autores a alta pressão pode afetar a conformação das proteínas levando a sua desnaturação, agregação ou gelatinização, dependendo do sistema protéico (tipo de proteína, pH, força iônica), pressão aplicada, temperatura e duração do tratamento. Os efeitos do tratamento sob alta pressão sobre as proteínas estão relacionados com a ruptura das interações nãocovalentes dentro das moléculas de proteínas e a subseqüente nova formação de pontes internamente, ou entre moléculas de proteínas. A alta pressão pode romper interações eletrostáticas. As pontes de hidrogênio não são afetadas pela alta pressão. As estruturas terciárias e quaternárias podem ser modificadas em pressões maiores que $200 \mathrm{MPa}$. As proteínas oligoméricas podem ser dissociadas em subunidades usando pressões moderadas (<150 MPa). 
MOLINA, PAPADOPOULOU e LEDWARD (2001) comprovaram que o uso da alta pressão pode melhorar a atividade emulsionante das proteínas de soja. Estudaram a influência do tratamento sob alta pressão (200 $600 \mathrm{MPa}$ ) no índice de atividade emulsificante (IAE) e a do índice de estabilidade da emulsão (IEE) sobre as frações 7S e 11S e isolados de soja em valores de $\mathrm{pH}$ de 6,5 e 7,5 em diferentes concentrações $(0,25$ $0,75 \%$ ). A fração $7 S$ exibiu o maior valor de IAE e hidrofobicidade superficial após o tratamento a $400 \mathrm{MPa}$, enquanto que a fração $11 \mathrm{~S}$ mostrou o mais alto IAE e hidrofobicidade superficial após o tratamento a $200 \mathrm{MPa}$. O isolado de soja revelou maior valor de IAE após o tratamento a $400 \mathrm{MPa}$, embora tenha apresentado baixa hidrofobicidade superficial.

MOLINA, DEFAYE e LEDWARD (2002) estudaram as propriedades de textura e capacidade de retenção de água em géis formados sob alta pressão (300-700 MPa/15 minutos). A 20\% de concentração, isolado de soja e suas maiores frações de globulinas $7 \mathrm{~S}$ e $11 \mathrm{~S}$ produziram géis auto-estáveis. Os géis induzidos sob alta pressão apresentaram menores valores de adesividade e dureza quando comparados com os géis formados pelo tratamento térmico $\left(95^{\circ} \mathrm{C} / 15\right.$ ou 30 minutos). O tratamento sob alta pressão melhorou a capacidade de retenção de água do géis formados pela fração 7S e em alguns casos do isolado de soja. As análises de calorimetria diferencial de varredura e eletroforese em gel de poliacrilamida mostraram evidências da desnaturação e agregação das proteínas durante a formação do gel, sendo intensificadas com o aumento da pressão.

ROESCH e CORREDIG (2003) estudaram emulsões de óleo em água, contendo diferentes porções de concentrado de soja, e analisaram suas características de estabilidade, tamanho das partículas, absorção superficial, microestrutura e propriedades reológicas. Observaram que o tratamento térmico de $82^{\circ} \mathrm{C}$ por 2 minutos, seguido de tratamento sob pressão de homogeneização de $80 \mathrm{MPa}$, resultou em emulsões com certas propriedades de gelatinização que permaneceram estáveis ao armazenamento por 20 dias a $4^{\circ} \mathrm{C}$.

APICHARTSRANGKOON (2003) submeteu concentrado hidratado de soja ( $80 \%$ de umidade) ao tratamento sob pressão de 200, 400, 600 e $800 \mathrm{MPa}$, a 20 e $60^{\circ} \mathrm{C}$ por 20 e 50 minutos. Após os tratamentos foram analisados o comportamento viscoelástico, solubilidade do nitrogênio e seus perfis eletroforéticos. Verificou que as características reológicas são mais afetadas pela temperatura do que pelo tratamento sob pressão e que há limitadas formações de pontes dissulfídicas nos sistemas 
induzidos de formação de gel pela temperatura e pressão.

MOLINA e LEDWARD (2003) investigaram os efeitos da combinação dos tratamentos térmico $\left(90^{\circ} \mathrm{C} / 15\right.$ minutos) e sob alta pressão (300$700 \mathrm{MPa}$ ) nas propriedades de textura dos géis de isolado de soja e das frações 7 S e 11 a $12 \%$ de concentração de proteína $(\mathrm{p} / \mathrm{v})$ em $\mathrm{pH}$ neutro. Evidenciaram que somente a fração $11 \mathrm{~S}$ forma gel quando tratada termicamente. Quando o tratamento térmico foi realizado antes do outro, apenas a fração $11 \mathrm{~S}$ formou gel auto-estável. No entanto, quando o tratamento sob pressão foi realizado antes do térmico todas as proteínas analisadas formaram géis auto-estáveis. As análises das características da textura e da capacidade de retenção de água dos géis formados comprovaram que a combinação do tratamento térmico e alta pressão oferece a possibilidade de desenvolver novos produtos com novas texturas, indicando a necessidade de outros estudos para investigar as causas dessas diferenças.

PUPPO et al. (2004) estudaram as mudanças físico-químicas induzidas pelo tratamento sob alta pressão isostático (200-600 MPa) em isolados de soja em pH 3,0 (IS3) e pH 8,0 (IS8). No IS8 foi observado aumento na hidrofobicidade superficial e agregação da proteína; redução do conteúdo de sulfidrila livre; desdobramento parcial das frações $7 S$ e 11 e mudanças na estrutura secundária (tornando-a mais desordenada). O IS3 foi parcialmente desnaturado, apresentando agregados insolúveis e maior desdobramento molecular. Esse isolado revelou decréscimo na estabilidade térmica, aumento da solubilidade protéica e da hidrofobicidade, decréscimo do conteúdo de sulfidrila livre e total desnaturação nos tratamentos de $400-600 \mathrm{MPa}$. Há outro relato na literatura sobre o efeito da alta pressão na indução da gelatinização em "leite" de soja, utilizando o sistema isostático. De acordo com os testes realizados por KAJIYAMA et al. (1995), o "leite" de soja mudou do estado líquido para sólido após o tratamento a $500 \mathrm{MPa}$ por 30 minutos. Quando submetido a pressões menores ou iguais a $500 \mathrm{MPa}$, por 10 minutos, o "leite" de soja permaneceu em estado líquido e melhorou sua estabilidade. Entretanto, ocorreu redução na sua capacidade emulsificante. A solubilidade da proteína foi afetada pelo tratamento sob pressão, mudando o ponto isoelétrico de $\mathrm{pH}$ 4,1-4,3 para 4,5-4,7. O "leite" original apresentou maior solubilidade em $\mathrm{pH}$ abaixo de 3,0 e moderada solubilidade em $\mathrm{pH}$ $5,7-6,7$. O tratamento sob pressão reduziu a solubilidade abaixo de $\mathrm{pH}$ 3,0 e aumentou a solubilidade acima de $\mathrm{pH}$ 5,6. 


\section{INTERAÇÕES ENTRE PROTEÍNA E OS POLISSACARÍDIOS PECTINA E CARRAGENA}

A interação entre proteínas e polissacarídios exerce influência direta sobre as propriedades macroscópicas dos alimentos, tais como fluidez, estabilidade, textura e sensação bucal. Segundo TOLSTOGUZOV (1991), as interações entre proteínas e polissacarídios podem resultar em três conseqüências: 1) co-solubilidade; 2) incompatibilidade e 3) complexação. DOUBLIER et al. (2000) revisaram as interações entre proteínas e polissacarídios sob o ponto de vista dos fenômenos segregativos e associativos de separação de fases com ênfase no mecanismo envolvido e na estrutura final dos sistemas terciários. KRUIF e TUINIER (2001) revisaram as interações entre proteínas e polissacarídios sob o ponto de vista termodinâmico, discutindo as situações nas quais esses biopolímeros interagem em soluções e citando alguns exemplos.

BENICHOU, ASERRÍN e GARTI (2002) afirmaram que sob condições específicas de proporções adequadas de proteína e polissacarídios $(\mathrm{pH}$, força iônica, temperatura e processo de mistura), as proteínas e polissacarídios formam complexos com propriedades funcionais melhores em comparação às proteínas e polissacarídios utilizados separadamente. Segundo GRINBERG e TOLSTOGUZOV (1997) e SYRBE, BAUER e KLOSTERMEYER (1998), os efeitos do pH no comportamento da mistura proteína-polissacarídio diferem dependendo da natureza do polissacarídio (neutro, carboxilado ou sulfatado). Para as misturas proteínapolissacarídios neutros, o pH afeta somente a auto-associação da proteína. A incompatibilidade da proteína-polissacarídio aumenta em pH próximo ao ponto isoelétrico ( $\mathrm{pl}$ ) da proteína, no qual há a tendência da proteína auto-associar-se. Para os sistemas proteína e polissacarídios aniônicos (carboxilados ou sulfatados), o pH exerce efeito de autoassociação da proteína e de associação cruzada da proteína e polissacarídios. Complexa coacervação é observada em $\mathrm{pH}$ inferior ao pl da proteína em que os dois polímeros apresentam cargas opostas. Em valores de $\mathrm{pH}$ acima do $\mathrm{pl}$ da proteína, ambos os polímeros têm cargas negativas, a complexação é inibida e pode ocorrer a incompatibilidade. Para os polissacarídios sulfatados, um complexo solúvel proteínapolissacarídio pode ocorrer em $\mathrm{pH}$ acima do $\mathrm{pl}$ resultando na atração entre os resíduos de proteína ( $\mathrm{NH} 3+$ ) e os do hidrocolóide (OSO3-). Essa atração é particularmente intensa quando ambos proteína e polissacarídio sulfatado estão carregados negativamente.

A pectina, polissacarídio aniônico carboxilado de alto peso molecular, é 
constituída principalmente do metil éster de ácido poligalacturônico que contém proporção variável de grupos metoxila. As pectinas podem ter alto ou baixo teor de metoxilação. As de alta apresentam grau de metoxilação (GM) maior que 50\%, geleificando em concentrações de 60 e $80 \%$ de sólidos solúveis e $\mathrm{pH}$ de 2,8 a 3,8. Podem ser utilizadas como estabilizante de proteínas em produtos a base de soja, como as misturas de proteínas de soja com sucos de frutas. As pectinas de baixa metoxilação apresentam GM inferiores a 50\%, podendo formar gel em concentrações de sólidos solúveis de 10 a 70\% e pH de 2,8 a 6,0, somente em presença de íons polivalentes como o cálcio e magnésio. Dentre essas pectinas encontram-se as amidadas, que contêm o grupo amida (TORREZAN, 2003).

MAROZIENE e KRUIF (2000) estudaram a influencia da pectina (baixo teor de metoxila-BTM; baixo teor de metoxila amidada-BTMA e alto teor de metoxila - ATM) sobre a estabilidade do leite. Em pH 6,7 com concentração $0,2 \%$ de BTMA ou ATM foi observada diminuição na capacidade de floculação das micelas de caseína, fato também observado no caso da pectina BTM em concentração de $0,1 \%$. Esse mecanismo envolve a exclusão das cadeias do polímero de pectina do espaço entre as partículas coloidais que induzem atração efetiva entre as micelas de caseína, o que pode causar a separação de fases se a atração for suficientemente forte. Em pH 5,3 as moléculas de pectina são adsorvidas pelas micelas de caseína. Em concentração de pectina não-suficiente para cobrir as micelas de caseína foi observado o aparecimento de pontes de floculação. Com o aumento da concentração de pectina o sistema torna-se estável.

A formação de complexos entre a pectina de maçã e a proteína isolada de soro de leite foram avaliados por ZALESKA, RING e TOMASIK (2000) mediante eletrossíntese das misturas aquosas. A formação dos complexos seguiu equação cinética de primeira ordem. As interações mais fortes entre a pectina e a proteína envolveram os grupos carboxílicos da pectina e as ligações peptídicas da proteína. Os complexos não formaram filmes.

A carragena, polissacarídio aniônico sulfatado extraído de certas espécies de algas vermelhas (Rhodophyceae), é altamente utilizado pela indústria de alimentos como agente espessante, geleificante e estabilizante. Segundo PENNA (2003) trata-se de galactana contendo D e L-galactose e 3,6 anidro-galactose. É constituída por três frações principais que se diferenciam pelo conteúdo e distribuição de grupos sulfato-éster e são 
designadas como: iota $(\mathrm{l})$, kappa $(\kappa)$ e lambda $(\lambda)$ carragena. O peso molecular e a estrutura dessas frações determinam suas propriedades funcionais. A 1 e $\kappa$-carragena apresentam capacidade para a formação de gel, já a $\lambda$-carragena atua apenas como espessante. A viscosidade da solução alcançada depende da concentração, temperatura, presença de outros sólidos, tipo da carragena e de seu peso molecular. A t-carragena geleifica mais fortemente na presença de íons cálcio, formando gel elástico, claro e livre de sinérese que se recompõe depois de cisalhado. $\mathrm{O}$ pH não constitui fator importante para a geleificação da $\kappa$-carragena, no entanto em pH abaixo de 4,0 pode não ocorrer a geleificação devido a hidrólise ácida (ELEYA e TURGEON, 2000). As proteínas com caráter anfótero precipitam com carragena se o $\mathrm{pH}$ da solução estiver abaixo do ponto isoelétrico. Em soluções que apresentam valores de $\mathrm{pH}$ acima do ponto isoelétrico ocorre forte interação entre as proteínas e a carragena.

O efeito de diferentes concentrações de $\kappa$-carragena sobre a força do gel, cinética de geleificação e microestrutura do gel de albumina de soro bovino (ASB) em diferentes condições de pH e força iônica com ou sem adição de cloreto de potássio, foi pesquisado por NEISER et al. (2000). Dois tipos distintos de efeitos foram observados. Alta força de gel nas condições do ponto isoelétrico da ASB ou ligeiramente acima desse, baixa força iônica e alta concentração de carragena $(\sim 0,4-1,0 \% \mathrm{p} / \mathrm{v}) \mathrm{e}$ menor força de gel em $\mathrm{pH}$ mais alto, força iônica total e baixa concentração de carragena ( 0,2-0,4\% p/v). O líquido removido do gel por centrifugação apresentou concentração de carragena mais baixa do que o gel original em baixo pH e força iônica, indicando separação de fase associativa. A cinética de gelatinização desses géis diferem do gel puro de ASB ou de carragena, sugerindo forte interação entre os polímeros.

PARK, CHO e RHEE (2001) estudaram o efeito da adição das gomas guar e carragena sobre as propriedades funcionais da proteína isolada de soja (PIS). A incorporação de ar e a estabilidade da espuma foram melhoradas nos sistemas contendo PIS pela adição crescente dessas gomas, sendo sempre superiores quando comparados aos sistemas sem a adição de guar ou carragena. O melhor valor de incorporação de ar e estabilidade da espuma foram alcançados quando foi utilizada a adição de uma dessas gomas na concentração de $0,5 \%$.

HUA, CUI e WANG (2003) investigaram as propriedades de formação de gel da proteína de soja quando utilizadas em misturas com gomas (carragena, xantana, alginato e locusta). A força do gel formado entre a 
proteína de soja e a carragena alcançou os limites mais altos e os mais baixos conforme a concentração dos constituintes da mistura, indicando a ocorrência de mudança de fase.

\section{EFEITO DA ALTA PRESSÃO SOBRE AS INTERAÇÕES PROTEÍNA- POLISSACARÍDIOS}

O tratamento sob alta pressão além de preservar os alimentos pode modificar as propriedades funcionais dos seus constituintes (MONTERO, FERNÁNDEZ-DIAS e GÓMEZ-GUILLÉN, 2002). Ao contrário do que ocorre no tratamento térmico, as moléculas pequenas como os aminoácidos, vitaminas e os componentes do sabor permanecem inalterados após o tratamento sob alta pressão. No entanto, as ligações não-covalentes das proteínas e moléculas maiores podem ser alteradas pelo tratamento sob alta pressão (O'REILLY et al. 2001). Em alta pressão (acima de $200 \mathrm{MPa}$ ) muitas proteínas tendem a sofrer desdobramentos e podem ocorrer re-associações de subunidades dissociadas de oligossacarídios (PUPPO et al. 2004).

GALAZKA, DICKINSON e LEDWARD (1999) compararam o efeito do tratamento térmico $\left(>80^{\circ} \mathrm{C}\right.$ por $2 \mathrm{~min}$ ) e do tratamento sob alta pressão isostática (> $200 \mathrm{MPa}$, por $20 \mathrm{~min}$ ) sobre as propriedades de emulsificação da globulina $11 \mathrm{~S}$ de Vicia faba $(\mathrm{pH}=8,0)$ adicionada de $\iota$ ou $\mathrm{\kappa}$-carragena. Na medida em que se aumentou a temperatura do tratamento ou a pressão houve tendência à diminuição da eficiência de emulsificação e de estabilidade da emulsão. A adição de $\imath$ ou $\kappa$-carragena (3:3-7:1 por peso) à proteína nativa sob baixa força iônica levou a obtenção de gotículas menores, cujo tamanho decresceu com o aumento da concentração desses polissacarídios e aumento da pressão aplicada (> $200 \mathrm{MPa}$ ). A presença de 1 -carragena levou a obtenção das menores gotículas na emulsão fresca e a melhor estabilidade em relação ao comportamento visual da emulsão já preparada. Em todos os casos, a presença de 1carragena melhorou a estabilidade da emulsão. No entanto, a presença de $\kappa$-carragena nas amostras tratadas $\left(<75^{\circ} \mathrm{C}\right)$ e não-tratadas termicamente causou rápida separação de soro, provavelmente devido a floculação depletiva. A força de interação da globulina 11S com 1 ou $\kappa-$ carragena dependem da densidade de carga do polissacarídio. A presença de polissacarídios nas amostras submetidas ao tratamento térmico e sob alta pressão inibiram a formação de agregados.

DICKINSON e JAMES (2000) estudaram a influência do tratamento sob 
alta pressão sobre as associações de $\beta$-lactoglobulina e pectina de baixo teor de metoxila em emulsões e géis. Observaram mudanças reológicas na emulsão causadas pela floculação das gotículas que foram mais evidentes em baixo $\mathrm{pH}$, particularmente próximo ao ponto isoelétrico. Mudanças no comportamento da emulsão indicaram complexação da proteína e pectina induzida pelo tratamento sob pressão. Em pH neutro, a presença de pectina durante o tratamento sob alta pressão contribuiu para o fortalecimento do gel.

GALAZKA, DICKINSON e LEDWARD (2000) avaliaram a influência da alta pressão (200 MPa, 20 minutos) sobre as interações da globulina $11 \mathrm{~S}$ de Vicia faba com a 1 -carragena em solução, na interface e propriedades de emulsão, em condições de baixa força iônica e pH=8,0. $A$ adição de $\mathrm{t}$-carragena à globulina $11 \mathrm{~S}$ reduziu a temperatura de desnaturação, o valor da entalpia e a hidrofobicidade superficial e protegeu a globulina contra a agregação induzida pela alta pressão.

\section{CONCLUSÃO}

O processo de alta pressão constitui tecnologia promissora para ser utilizada em alimentos, visto que os danos aos aspectos sensoriais são mais suaves quando comparados com as tecnologias convencionais. Os aspectos envolvidos e estudos discutidos neste trabalho mostraram que é possível a aplicação da tecnologia de alta pressão para produtos a base de proteínas e polissacarídios. Essa tecnologia pode ser aplicada para controlar ou modificar as propriedades funcionais tecnológicas das proteínas e das interações entre proteínas e polissacarídios (pectina e carragena). Pode ser utilizada também em combinação com tratamento térmico e oferecer novas possibilidades de desenvolvimento de produtos, assim como de novas texturas em produtos existentes e outras futuras aplicações. Outros estudos devem ser conduzidos para o completo conhecimento dos mecanismos e aspectos físicos e químicos envolvidos nas interações entre proteínas e polissacarídios.

\section{Abstract}

REVIEW: EFFECT OF HIGH PRESSURE TREATMENT ON SOY PROTEIN FUNCTIONAL PROPERTIES AND PROTEIN - POLYSSACCHARIDE INTERACTION

In this literature review article the soy protein composition, functional properties and the effects of high pressure on technological functional properties of soy products 
were approached. The protein-polysaccharide interactions (pectin and carrageenan) and the effects of high-pressure treatment in these interactions were also studied. The researches reviewed in this work show that there is a potential application for high-pressure technology in protein products mixed with polysaccharides. This technology can be used to control or modify the functional properties of proteins as well for new products development and future applications.

KEY-WORDS: SOY PROTEINS; FUNCTIONAL PROPERTIES; PECTIN; CARRAGEENAN.

\section{REFERÊNCIAS}

1 ANSTINE, T. T. High-pressure processing for safe, quality foods. Cereal Foods World, v. 48, n. 1, p. 5-8, 2003.

2 ANTHONY, M. S.; POTTER, S. M.; SCHONFELD, G.; SCOTT, L. W.; WILLIAMS, C. L. Soy protein and health: discovering a role for soy protein in the fight against coronary heart disease. St. Louis: Protein Technologies International, 1996. 24 p.

3 APICHARTSRANGKOON, A. Effects of high pressure on rheological properties of soy protein gels. Food Chemistry, v. 80, n. 1, p. 55-60, 2003.

4 BENICHOU, A.; ASERIN, A.; GARTI, N. Protein polysaccharide interactions for stabilization of food emulsions. Journal of Dispersion Science and Technology, v. 23, n. 1-3, p. 93-123, 2002.

5 Cheftel, J. C.; CUQ, J. L.; LORIENT, D. Proteínas alimentarias: bioquímica, propriedades funcionales, valor nutricional e modificaciones químicas. Zaragoza: Editorial Acribia, 1989. $346 \mathrm{p}$.

6 DAMODARAN, S. Refolding of thermally unf3olded soy proteins during the cooling regime of the gelation process: effect on gelation. Journal of Agricultural and Food Chemistry, v. 36, n. 2, p. 262-269, 1988.

7 DICKINSON, E.; JAMES, J. D. Influence of high-pressure treatment on $\beta$-lactoglobulin-pectin associations in emulsions and gels. Food Hydrocolloids, v. 14, n. 4, p. 365-376, 2000. 
8 DOUBLIER, J. L.; GARNIER, C.; RENARD, D.; SANCHEZ, C. Protein-polysaccharide interactions. Current Opinion in Colloid \& Interface Science, v. 5, n. 3-4, p. 202-214, 2000.

9 ECIRTEC. Equipamentos e Acessórios Industriais Ltda. Notícias sobre agro-business e tecnologia. Disponível <http:// br.groups.yahoo.com/group/ecirtec/message/19> Acesso em: 05/ 09/2003.

10 ELEYA, M. M. O.; TURGEON, S. L. The effects of $\mathrm{pH}$ on the rheology of $\beta$-lactoglobulin/ $\kappa$-carrageenan mixed gels. Food Hydrocolloids, v. 14, n. 3, p. 245-251, 2000.

11 GALAZKA, V. B.; DICKINSON, E.; LEDWARD, D. A. Emulsifying behaviour of $11 \mathrm{~S}$ globulin Vicia faba in mixtures with sulphated polysaccharides: comparison of thermal and high-pressure treatments. Food Hydrocolloids, v. 13, n. 5, p. 425-435, 1999.

12 GALAZKA, V. B.; DICKINSON, E.; LEDWARD, D. A. Influence of high pressure on interactions of $11 \mathrm{~S}$ globulin Vicia faba with tcarrageenan in bulk solution and at interfaces. Food Hydrocolloids, v. 14, n. 6, p. 551-560, 2000.

13 GARcíA, M. C.; TORRE, M.; MARINA, M. L.; LABORDA, F. Composition and characterization of soybeans and related products. Critical Reviews in Food Science and Nutrition, v. 37, n. 4, p. 361-391, 1997.

14 GRANT, S.; PATTERSON, M.; LEDWARD, D. Food processing gets freshly squeezed. Chemistry \& Industry, n. 2, p. 55-58, 2000.

15 GRINBERG, V. Y.; TOLSTOGUZOV, V. B. Thermodynamic incompatibility of proteins and polysaccharides in solutions. Food Hydrocolloids, v. 11, n. 2, p. 145-158, 1997.

16 HASHIZUME, K.; NAKAMURA, N.; WATANABE, T. Influence of ionic strength on conformation changes of soybean proteins caused by heating, and relationship of its conformation changes to gel formation. Agricultural and Biological Chemistry, v. 39, n. 7, 1339-1347, 1975. 
17 HUA, Y.; CUI, S. W.; WANG, Q. Gelling property of soy protein gum mixtures. Food Hydrocolloids, v. 17, n. 6, p. 889-894, 2003.

18 KAJIYAMA, N. ; ISOBE, S. ; UEMURA, K. ; NOGUCHI, A. Changes of soy protein under ultra-high hydraulic pressure. International Journal of Food Science and Technology, v. 30, n. 2, p. 147-158, 1995.

19 KESTER, J. J.; RICHARDSON, T. Modification of whey proteins to improve functionality. Journal of Dairy Sciences, v. 67, n. 11, p. 2757-2774, 1984.

20 KITAMURA, K. Genetic improvement of nutritional and food processing quality in soybean. Japan Agricultural Research Quarterly, v. 29, n. 1, p. 1-8, 1995.

21 KRONES. Sucos: consumo da bebida a base de soja aumenta no Brasil. Boletim Eletrônico da Krones S/A, n.6, setembro de 2002. Disponível http://www.krones.com.br/Boletim/Edicao6/ materia6.htm [acesso em 05/09/2003].

22 KRUIF, C. G.; TUINIER, R. Polysaccharide protein interactions. Food Hydrocolloids, v. 15, n. 4-6, p. 555-563, 2001.

23 LIU, K. Soybeans: chemistry, technology, and utilization. New York: Chapman \& Hall. 1997. 532 p.

24 MAROZIENE, A.; KRUIF, C. G. Interaction of pectin and casein micelles. Food Hydrocolloids, v. 14, n. 4, p. 391-394, 2000.

25 MATTIL, K. F. The functional requirements of proteins for foods. Journal of the American Oil Chemists' Society, v.48, n. 9, p. 477-480, 1971.

26 MELLO, P. C. Brasileiro já não abre mão de supérfluos. O Estado de São Paulo/Economia, Terça-feira, 10 de setembro de 2002. Disponível http://www5.estado.com.br/editorias/2002/09/10/ eco029.html [acesso em 05/09/2003].

27 MESSENS, W.; VAN CAMP. J.; HUYGHEBAERT, A. The use of high pressure to modify the functionality of food proteins. Trends in Food Science and Technology, v. 8, n. 4, p. 107-112, 1997. 
28 MEYER, R. S.; COOPER, K. L.; KNORR, D.; LELIEVELD, H. L. M. High-pressure sterilization of foods. Food Technology, v. 54, n. 11, p. $67,72,2000$.

29 MOLINA, E.; DEFAYE, A. B.; LEDWARD, D. A. Soy protein pressure-induced gels. Food Hydrocolloids, v. 16, n. 6, p. 625632, 2002.

30 MOLINA, E.; LEDWARD, D. A. Effects of combined high-pressure and heat treatment on the textural properties of soya gels. Food Chemistry, v. 80, n. 3, p. 367-370, 2003.

31 MOLINA, E.; PAPADOPOULOU, A.; LEDWARD, D. A. Emulsifying properties of high-pressure treated soy protein isolate and $7 \mathrm{~S}$ and $11 \mathrm{~S}$ globulins. Food Hydrocolloids, v. 15, n. 3, p. 263-269, 2001.

32 MONTERO, P.; FERNÁNDEZ-DIAZ, M. D.; GÓMEZ-GUILLÉN, M. C. Characterization of gelatin gels induced by high pressure. Food Hydrocolloids, v. 16, n. 3, p. 197-205, 2002.

33 NEISER, S.; DRAGET, K. I.; SMIDSR $\varnothing D$, O. Gel formation in heat-treated bovine serum albumin - $\kappa$-carrageenan systems. Food Hydrocolloids, v. 14, n. 2, p. 95-110, 2000.

34 NUTRISOY. Benefícios à saúde quadruplicam consumo de soja no Brasil. Disponível http://www.nutrisoy.com.br/noticias/ noticias.asp?nt=58. Acesso em 05 set. 2003.

35 O'REILLY, C. E.; KELLY, A. L.; MURPHY, P. M.; BERESFORD, T. P. High-pressure treatment: applications in cheese manufacture and ripening. Trends in Food Science Technology, v. 12, n. 2, 51-59, 2001.

36 PARK, S. K.; CHO, J.M.; RHEE, C. O. Effect of guar gum, carrageenan and calcium chloride on foaming properties of soy protein isolate. Food Science Biotechnology, v. 10, n. 3, p. 257-260, 2001.

37 PENNA, A. L. B. Hidrocolóides: usos em alimentos. Caderno de Tecnologia de Alimentos \& Bebidas. Disponível em: http:// www.vistafi.com.br/Main/revistas/ed_17/pdf/p\&da.pdf. Acesso: 06 dez. 2003. 
38 PETRUCELLI, S.; AÑON, M. C. pH induced modifications in the thermal stability of soybeans protein isolates. Journal of Agricultural and Food Chemistry, v. 44, n. 10, p. 3005-3009, 1996.

39 PUPPO, C.; CHAPLEAU, N.; SPERONI, F.; LAMBALLERIEANTON, M. de; MICHEL, F.; AÑON, C.; ANTON, M. Physicochemical modifications of high-pressure-treated soybean protein isolates. Journal of Agricultural and Food Chemistry, v. 52, n. 6, p. 1564-1571, 2004.

40 ROESCH, R.; CORREDIG, M. Texture and microstructure of emulsions prepared with soy protein concentrate by high-pressure homogenization. Lebensmittel Wissenschaft and Technologie, v. 36, n. 1, p. 113-124, 2003.

41 SAN MARTÍN, M. F.; BARBOSA-CÁNOVAS, G. V.; SWANSON, B. G. Food processing by high hydrostatic pressure. Critical Reviews in Food Science and Nutrition, v. 42, n. 6, p. 627645, 2002.

42 SGARBIERI, V. C. Proteínas em alimentos protéicos: propriedades, degradações, modificações. São Paulo: Livraria Varela, 1996. 517 p.

43 SOY proteins. Disponível em: <http://www.dairyfoods.com/articles/ 2000/1200/0012it.htm> Acesso: 15 jun. 2002.

44 SYRBE, A.; BAUER, W. J.; KLOSTERMEYER, H. Polymer science concepts in dairy systems - an overview of milk protein and food hydrocolloid interaction. International Dairy Journal, v. 8, n. 3, p. 179-193, 1998.

45 TOLSTOGUZOV, V. B. Functional properties of food proteins and role of protein-polysaccharide interaction. Food Hydrocolloids, v. 4, n. 6, p. 429-468, 1991.

46 TORREZAN, R. Geléia de fruta. In: EMBRAPA Informação Tecnológica. Serviço Brasileiro de Apoio às Micro e Pequenas Empresas. Iniciando um pequeno grande negócio agroindustrial: frutas em calda, geléias e doces. Brasília, 2003. p. 31-46. 
47 UTSUMI, S.; KINSELLA, J. E. Forces involved in soy protein gelation: effects of various reagents on the formation, hardness and solubility of heat-induced gels made from 7S, 11S, and soy isolate. Journal of Food Science, v. 50, n. 5, p. 1278-1282, 1985.

48 WAGNER, J. R.; GUÉGUEM, J. Surface functional properties of native, acid-treated, and reduced soy glicinin. 1. Emulsifying properties. Journal of Agriculture and Food Chemistry, v. 47, n. 6, p. 2181-2187, 1999.

49 WILLIAMS-CAMPBELL, A. M.; SOLOMON, M. B. Reduction of spoilage microorganisms in fresh beef using hydrodynamic pressure processing. Journal of Food Protection, v. 65, n. 3, p. 571-574, 2002.

50 YAMAUCHI, F.; YAMAGISHI, T.; IWABUCHI, S. Molecular understanding of heat-induced phenomena of soybean protein. Food Reviews International, n. 7, v. 3, 283-322, 1991.

51 ZALESKA, H.; RING, S. G.; TOMASIK, P. Apple pectin complexes with whey protein isolate. Food Hydrocolloids, v. 14, n. 4, p. 377-382, 2000. 